\title{
Motor Learning Measuring Tools: A Design and Implementation Using Sensor Technology for Preschool Education
}

\author{
https://doi.org/10.3991/ijim.v15i17.25321 \\ Anton Komaini ${ }^{(凶)}$, Hendra Hidayat, Ganefri, Alnedral, \\ Yanuar Kiram, Gusril, Deby Tri Mario \\ Universitas Negeri Padang, Padang, Indonesia \\ antonkomaini@fik.unp.ac.id
}

\begin{abstract}
Motor learning in preschool education is very important to be a concern because it has an impact on the growth and development of children, and their mental abilities. This study aims to design and implement motor learning measuring tools using sensor technology for preschool education. This measuring instrument is expected to have a good performance in assessing motion in children, such as running, walking, and jumping. This type of research is development research with three stages, namely, phase I needs analysis and designing motor learning measuring tools, phase II, implementation of motor learning measuring tools, and developing motor learning measuring tools, phase III, evaluating of motor learning measuring tools and dissemination. However, this research is only limited to the stage of designing and implementing motor learning measuring tools. This research involved instrumentation experts and Kindergarten students, with a total sample of 65 students, using the purposive sampling technique. The result of this study is a sensor technology-based motor learning measuring instrument that can make an objective, easy and practical assessment. This measuring instrument can measure motor skills in locomotor movements, namely, running, walking, and jumping. Furthermore, the results of the implementation showed an increase in the motor skills of children aged for the better. So it is hoped that this measuring tool can be used by the wider community in an effort to improve preschool education learning.
\end{abstract}

Keywords-motor learning, measuring instruments, preschool education, sensory technology

\section{Introduction}

Education is a learning process that is held interactively, inspiring, fun, challenging, motivating children to be active, and providing sufficient space so that children are creative and independent according to their talents, interests, physical and psychological development of children. One form to achieve learning objectives, especially in preschool education education is to develop materials and tools for motor learning 
in children. This learning innovation refers to the demands that are integrated with information technology according to the demands of the digital era [1-5]. Learning occurs through dynamic interactions between the physical and social environment [6]. Research shows many benefits that children get from learning outdoors such as physical improvement, motor development, and broader holistic development [7]. Generally, children who study in Kindergarten do not yet have good motor skills compared to children at the elementary school level. For this reason, preschool education motor skills need to be trained through activities that are in accordance with the stages of development. Learning that is systematically arranged, fun, inspiring, and motivating will enable children to learn independently. Then, specifically learning is focused on what, how, and where according to the needs of children [8].

Preschool education learning methods that still use traditional methods have many weaknesses, such as being centered on all children without paying attention to the special characteristics of children [9]. As a result, the movement learning given to children is not fulfilled optimally. The theory of motor development needs to be mastered by the teacher in planning activities such as the choice of movement tasks, equipment, and the movement environment so that children can get the correct motion experience [10]. Knowledge of the sequence of motor development is very valuable because it can inform the teacher about the type of physical activity provided according to the child's development, this stage can also serve as an assessment of the child's basic movement skills [11]. Therefore, teachers as educators are required to be creative and innovative in providing learning related to children's movements.

The development of basic movements in children can be known from locomotor, non-locomotor, and manipulative movements. These movements have fundamental differences in their characteristics that need to be learned and trained for kindergarten-age children. If the child masters basic movements with the correct concept of motion learning, then the child has the foundation to learn movement skills well, not least in various sports in the future. Basic movement skills are complex elements needed to perform a game, sport, or other physical activity. Motor skill development is a potential mechanism to reduce the negative impact of physical activity, health, and obesity rates [12-13]. The level of motor skills of children is closely related to health, such as cardiorespiratory and fitness [14], as well as organized physical activity [15]. The reciprocal and dynamic relationship between physical activity and motor skills [16-19], has shown that motor skills can improve health in children such as cardiorespiratory fitness, muscle strength, and endurance. This positive relationship is strengthened with increasing age [20-21]. Physical activity involves both physical and physiological components such as cardiorespiratory fitness, musculoskeletal fitness (ie, muscular endurance and strength), and flexibility [22]. Motor skills also have an impact on children's physical, social, and cognitive development [23], [12]. Children and adolescents should engage in at least 1 hour of moderate to vigorous physical activity each day, but studies from around the world show that children and adolescents typically fall well below this target [24-25].

Based on the results of research on basic movement skills in the city of Padang, Indonesia, it was found that $36.07 \%$ were in a low category and $18.98 \%$ of children's basic movement skills were in a low category. This data is reinforced by the findings of Bakhtiar [26] which states that boys and girls in rural and urban areas in West Sumatra 
are very delayed in locomotor skills and control of objects. Movement delays in children if left unchecked will cause several pathological threats, such as 1) Asymmetrical or unbalanced movements between the left and right limbs, 2) Persistence of primitive reflexes, 3) Hyper/hypotonia or impaired muscle tone, 4) Hyper/hypertension. hyporeflexia or impaired reflexes of the body, 5) The presence of uncontrolled movements [27]. Furthermore, the lack of basic movement skills of children will cause impaired sensory function, cause body defects, obesity, imitation movement disorders, malnutrition [56], have difficulty in regulating body balance, slow reactions, and poor coordination.

Based on further studies, this problem is influenced by various factors, such as lack of infrastructure for motor development, the absence of technology-based measuring tools for children's basic movement skills, so that teachers and parents rarely evaluate children's basic movements. In addition, the problem is also influenced by a very narrow environment, the emergence of electronic devices that can produce games such as play stations, online games, smartphones, causing children to be lazy to move inactive games, plus the demands of parents on preschool education. to be able to read, write and count. This situation, if left unchecked, will make the basic movement skills of preschool education lower. One of the factors that affect the low basic movement skills of children is the unavailability of basic motion measuring tools based on sensor technology, where so far the existing motor skills measuring tools are still using the manual method. Therefore, it is necessary to develop a measuring instrument for children's basic movement skills by utilizing technology. This study aims to design and implement a measuring tool for motor skills that can make an objective, easy and practical assessment of locomotor motion (running, walking, jumping).

\section{$2 \quad$ Literature review}

\subsection{Basic movement skills}

Basic motor skills are the basis for developing more complex motor skills [28]. Basic movement skills are developed in preschool education. This is an initial provision to acquire general movement skills. Further, it will be needed as a basis for the development of more specialized motor skills. Basic movements are body movements that use large muscles or most of the muscles in the body or all limbs that are influenced by their own maturity. Basic locomotion skills are movement patterns that involve body parts such as the legs, arms, trunk, and head, and include skills such as walking, jumping, catching, throwing, hitting, and balancing.

Basic movements such as locomotor movements (eg, running, walking, jumping), should be taught in a way that is appropriate for the child's development in developing his skills [29-31]. If children are not given the opportunity to learn basic movements, then they will be at risk of experiencing delays in their development [32]. Fundamental movement skills are often regarded as the underlying mechanism of physical activity [33-35] and as a health-related correlation of weight and fitness status. Physical activity can be achieved with various forms of play through various learning motions. Some of the benefits of physical activity in education that can nourish the mentality of 
students such as, exercise which can reduce stress and feelings of happiness, exercise can increase brain power, exercise can increase self-confidence [36].

\subsection{Motor learning}

Movement skills possessed by children do not occur in an instant way without a good process. The process of creating good movement skills can be done from an early age. At that age, it is necessary to provide movement learning to children by paying attention to the characteristics of each child. Motor activity is not only derived from the individual characteristics of the child, but also from the family and school environment [37]. Therefore, a teacher needs to know and understand the stages in motor learning given to children.

Motor learning is grouped into three stages, namely: (1) stages of understanding the concept of motion (Cognitive Stage), (2) stages of motion (Motor Stage), and (3) stages of autonomy (Autonomous Stage). Here's the explanation:

1. The stage of understanding the concept of motion is the stage where the child must understand and understand the concept of motion to be carried out. Understanding the concept of motion can be done by finding out what, how, and why motor activities are carried out. By understanding the concept of motion, the child will more easily carry out the instructed motion.

2. Stages of motion (Motor Stage). After knowing the concept of motion is to understand the stages of motion to be carried out. At this stage, the child understands the stages of motion by carrying out the movement activities learned.

3. Stages of autonomy (Autonomous Stage). The autonomy stage is where the child has mastered well-instructed movements and the movements have become automatic.

Based on the stages of motor learning, the development of basic motion learning models will use these stages by providing an understanding of the concept of motion, providing examples of motion, and forms of repetition of activities [38].

\subsection{Sensor limit switch}

The limit switch is a type of sensor that functions to detect the movement of moving machine parts, such as cylinders and others. When the lever or can also be called a cam hits or presses the head of the limit switch, this sensor immediately works so that the contacts on the inside will also work. When the sensor is working, it can be directly connected to other devices or components such as solenoid valves or indicator lights. There are various types and sizes of this sensor, but in principle, the work is exactly the same. The head of this limit switch can be pressed left and right at a certain angle, for example, 45 degrees, then it will work. While on the inside there is a micro switch that functions to continue the movement given by the head of the limit switch on the outside, so that when the micro switch is depressed it contacts directly (NO and $\mathrm{NC}$ contacts). 


\section{$3 \quad$ Research methods}

This research method uses a research and development approach [39]. This research development approach is carried out in 3 stages, namely: phase I, needs analysis [55], and designing motor learning measuring tools, phase II, implementation of motor learning measuring tools, and developing motor learning measuring tools, phase III, evaluating of motor learning measuring tools and dissemination. however, this research is only limited to the stage of designing and implementing motor learning measuring tools. This study involved instrumentation experts and Kindergarten students, with a total sample of 65 students in preschool education education in the city of Padang, Indonesia, using the purposive sampling technique. This study aims to design and implement motor learning measuring tools using sensor technology for preschool education, where so far the existing motor skills tests are still using the manual method. The framework of the focus and limitations of the research is presented in Figure 1 below.

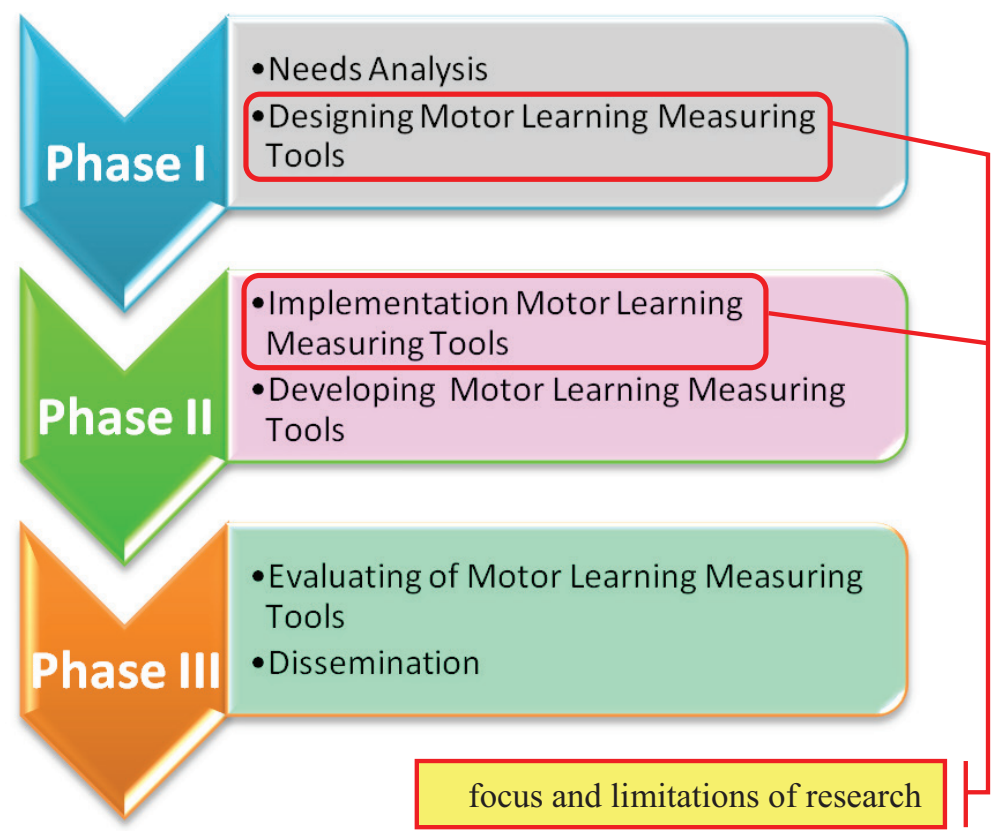

Fig. 1. Framework for research stages of developing motor learning measuring tools

At the design stage of this tool, several stages were carried out, namely 1) measuring instrument design, 2) design validation and 3) design revision. Furthermore, at the implementation stage there are several indicators, namely, 1) Child Can Jump to the 4-way cube sequentially, 2) Jumping forward on two legs, 3) Jump to the left, right, and back, 4) Jumping in place with two legs, 5) Jump in place on one leg 3 times in a row with the left and right feet alternately, 6) The child runs through the cube in sequence, 
7) Horse Running (Gallop) In a straight line, 8) Run backward in a straight line, 9) The child walks through the Cube in sequence, 10) Walking tiptoe forward with the tips of the toes, 11) Walking backward in a straight line. Assessment of quantitative to qualitative data from the results of increasing motor skills of preschool education refers to Table 1 below.

Table 1. Conversion of quantitative data to qualitative data

\begin{tabular}{|l|l|}
\hline \multicolumn{1}{|c|}{ Average Score } & \multicolumn{1}{|c|}{ Qualification Motor Ability Preschool Education } \\
\hline $64-90$ & Ability Can \\
\hline $36-63$ & Can with Help \\
\hline $10-35$ & Can't \\
\hline
\end{tabular}

\section{$4 \quad$ Results}

\subsection{Measuring tool design}

To design a test tool for basic motor skills (Fundamental Motor Skills)/FMS, it is done through literature studies both sourced from the internet, reference books, and relevant scientific journals. The design the tool according to Figure 2 below.

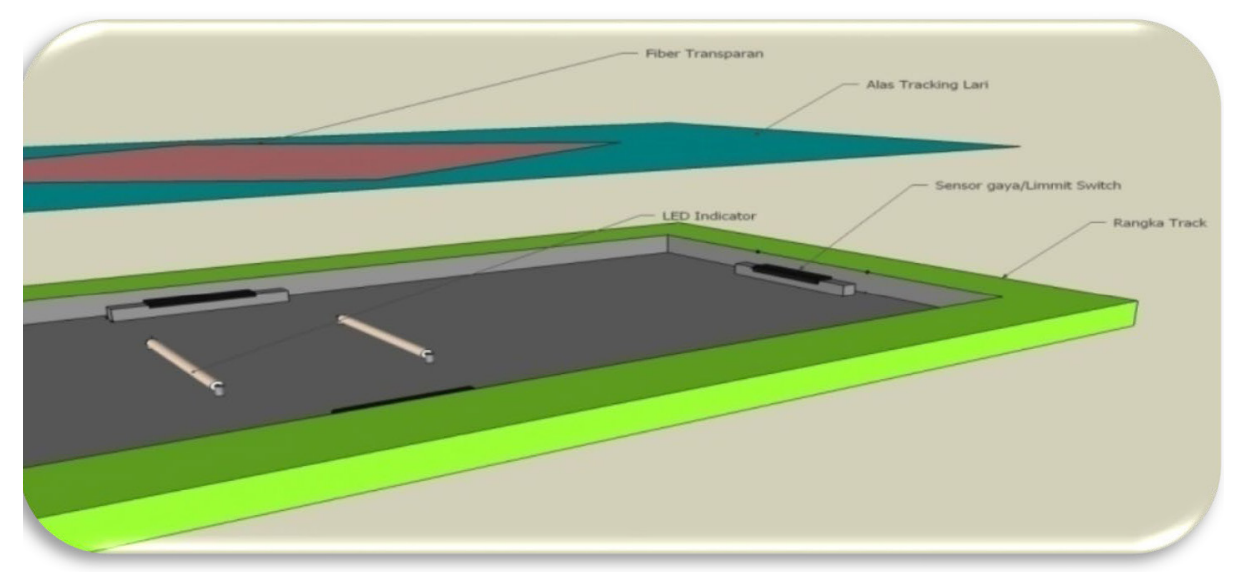

Fig. 2. Components of the preschool education motor skills measurement tool

The basic movement skill test is made with the following components: a track frame made of stainless steel that is lightweight and anti-rust and portable, making it easy to move and store. The sensor used is the Limit switch sensor, the footing used is a $1 \mathrm{~cm}$ thick field carpet, transparent fiber to provide an LED light indicator when the tool is used. 
The design of measuring instruments for basic movement skills for preschool education is adapted to locomotor motion theory [40]. Based on this, a design is shown in Figure 3.

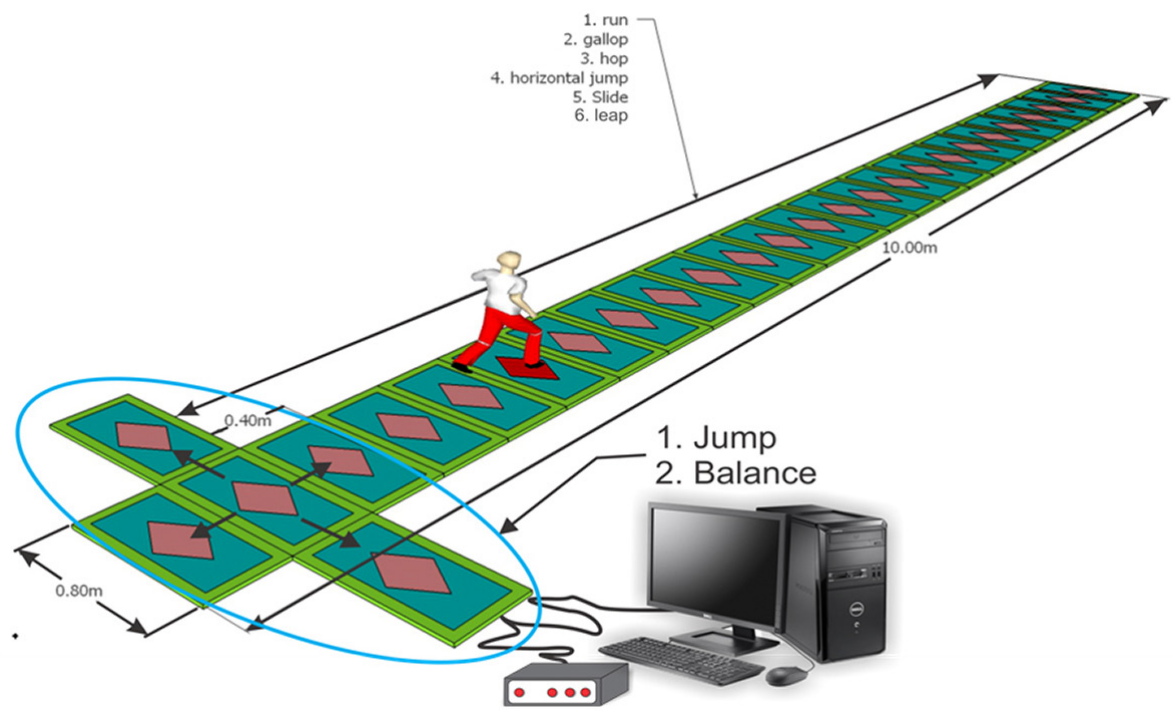

Fig. 3. Design of motor skills measurement tool for preschool education

\subsection{Expert suggestions and design revisions}

At this stage, the researcher got some input from experts so that a new design of the measuring instrument for preschool education movement skills was obtained. The revision is in the form of improving the length of the running track which was previously only 5 meters, then it was extended to 10 meters. Play is important for a child, games can provide opportunities to practice skills repeatedly and can develop ideas according to their own ways and abilities, and the media for playing a child must be wider and freer to develop the child's motor skills., so that it can be concluded that the distance required for the child to do the running and jumping test must be wider and free so that the child can move freely and freely.

The process of developing digital-based preschool education basic movement skills test instruments is carried out through the first stages, namely looking for potential problems, data collection, product design, design validation, design revision. Based on the design validation carried out by motorists, an instrument is produced that can be used to measure movement skills of preschool education. The following is a picture of a measuring instrument for basic movement skills for preschool education after being validated by a motorist. Design motor skills measuring instrument according to the following Figure 4. 


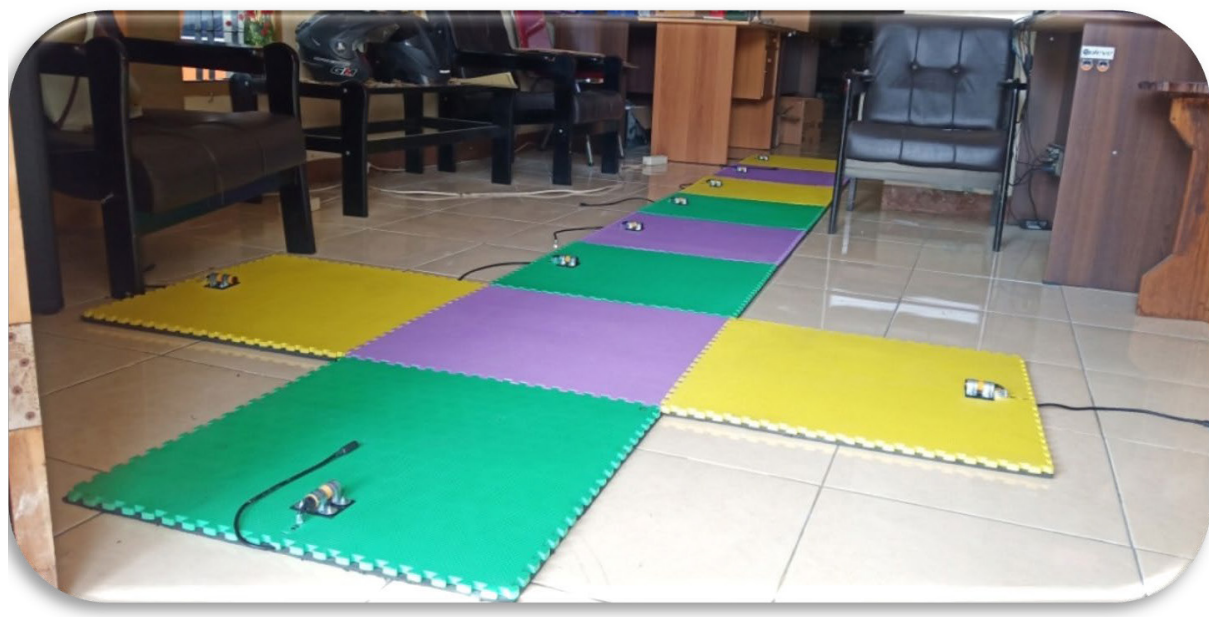

Fig. 4. Measuring tool for preschool education movement skills

How to use measuring tools: Rating Jump

a. The tool consists of two parts, namely the part in the form of a plus sign and the straight part which has a distance of 10 meters.

b. The child stands in the middle of the square-shaped like a plus sign.

c. The child performs a jumping motion with both legs sequentially from cube one which has sensor one and returns to the initial cube and makes a second jump to cube two, the child jumps back to the initial cube and repeats the movement until it reaches the fourth cube.

d. At the same time the sensor will detect and calculate the time of the child's jump so that the output is in the form of time and the sensor will translate the number of movements by displaying the motion detected by the sensor when the child makes a jump, and the results will be displayed on the LCD in the form of the time and number of lights that are lit. which indicates the child's movement is correct and detected by the sensor.

\section{Run rating}

a. The child stands on the central cube which is in the middle of the cube that forms a plus sign

b. The child runs towards the ninth cube (the last cube) and after the child arrives at the cube the child makes a turning movement and runs back towards the central cube (the cube in the middle of the cube in the form of a plus sign)

c. When the child finishes doing the movement, the sensor will detect the movement and calculate the time since the child made the first running movement until the child returns to the central sensor.

d. The calculation results will be displayed on the LCD in the form of time and motion detection performed by the child which is translated into a light that turns on when 
the sensor detects the child's movement and the light will turn off when the sensor does not detect the child's movement.

Road appraisal

In the walking assessment, the test mechanism is exactly the same as the assessment in the running test, starting from the starting point, calculating and detecting sensors, except that the test carried out by the child is carried out by walking instead of running.

\section{Discussion}

The results of the study have created a motor skills test tool from the locomotor component. This tool can measure a child's ability to walk, run and jump. The results of Pustisek et al research [41] regarding motor learning with the use of technology explain that technology can outperform the human senses in almost all aspects, there is no doubt at all that science and technology can help athletes achieve maximum performance. The application of this science and technology can provide a significant competitive advantage. In identifying and evaluating a large number of technological solutions available for motor skills assessment. While promising, there is still a need for large-scale studies to validate this approach in terms of accuracy, repeatability, and usability, where interdisciplinary collaboration between researchers and practitioners is supported by transparent results.

Children can walk at about 12 months of age, but the walking process will develop more smoothly according to the mechanics of the movement. The legs and arms are alternated and the placement of the legs is still not stable, but the walking pattern is efficient. Walking has become more automatic, so children can walk and talk or walk while manipulating something in their hands [42]. Running is a continuation of walking skills, the initial characteristic of running is through footwork, while flying the feet still have a distance limit with movement. Swing opposite arms between legs and arms. The arm swing works in conjunction with body rotation, forward and backward in sprinting. The basic abilities that must be possessed by children are good balance, motor coordination skills, movement planning. Children can jump in simple forms before the age of two. Jumping is a task in which the body is pushed off the ground with one foot or two from the ground two feet high.

A suitable and good movement program can form and develop children's basic movement skills. For this reason, it is very important to emphasize the movement development program in kindergarten. Furthermore, educators are encouraged to be able to take advantage of children's natural ability to move and integrate with organized motor skills programs into daily activities. The creation of this motor skill measuring tool is expected to be able to evaluate children's basic movements so that teachers and parents, and related parties can provide knowledge to children about basic movements that have an impact on the physical activities children do every day. Findings by the American Physical Activity Guidelines Advisory Committee (2018) stated that physically active children can reduce the risk of being overweight, cardiovascular disease, osteoporosis, and diabetes, improve mental health, higher self-esteem, and better emotional independence [43]. 
Furthermore, the results of the implementation of this tool are presented in the following Figure 5.

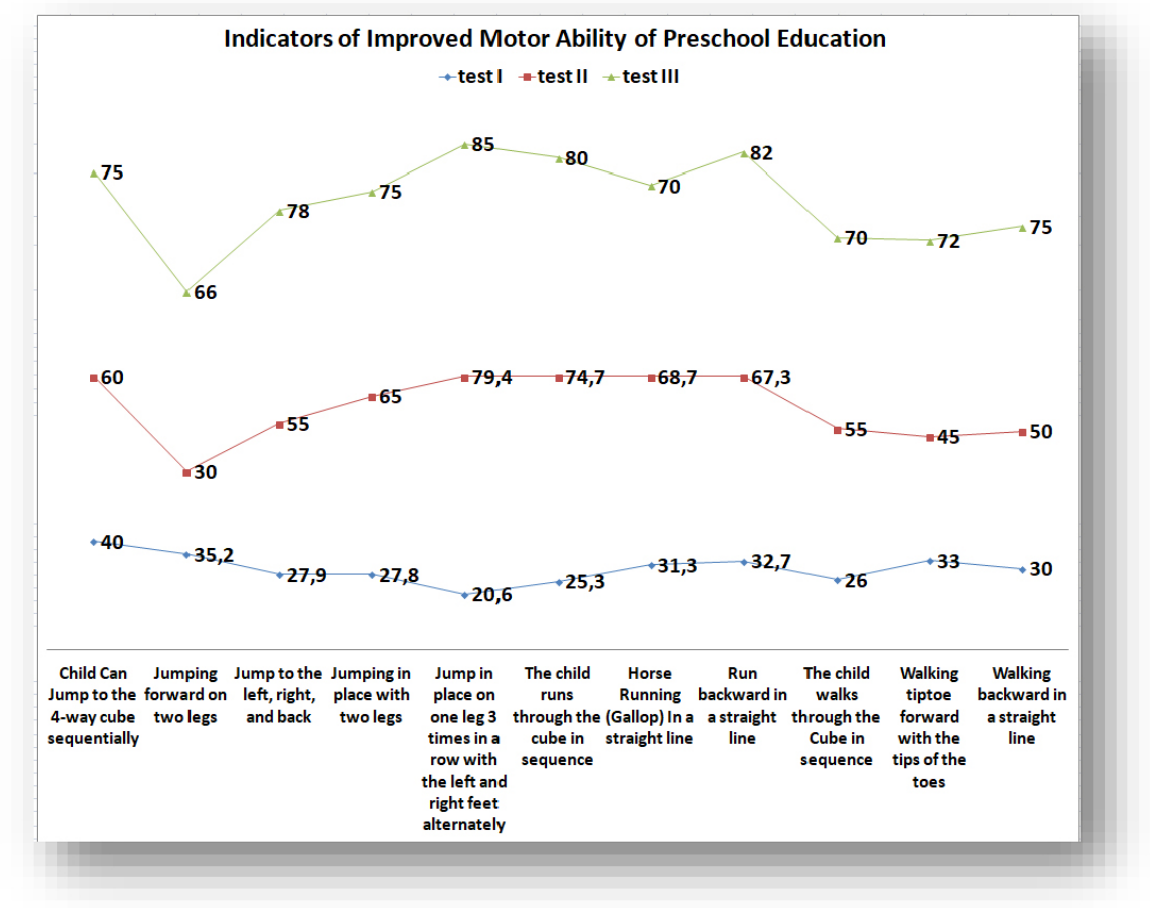

Fig. 5. Improved motor skills of preschool education

Increased motor skills of preschool education can be seen from several indicators, namely, 1) Child Can Jump to the 4-way cube sequentially, 2) Jumping forward on two legs, 3) Jump to the left, right, and back, 4) Jumping in place with two legs, 5) Jump in place on one leg 3 times in a row with the left and right feet alternately, 6) The child runs through the cube in sequence, 7) Horse Running (Gallop) In a straight line, 8) Run backward in a straight line, 9) The child walks through the Cube in sequence, 10) Walking tiptoe forward with the tips of the toes, 11) Walking backward in a straight line. The results of the implementation show that the increase is not as high, of course, this is influenced by various factors, such as the family and social environment, stimulus, at school, growth, and development of children, as well as adequate nutrition [44-50], including mental maturity, locus of control [44-50, 57]. Furthermore, from the results of this application, it can be seen that the jump in place on one leg 3 times in a row with the left and right feet alternately has the highest increase with a value of 85 , meaning that there are already people who have the ability to do it, and there is a value of 66 which increases already good but not optimal in the aspect of jumping forward on two legs. The role of technology in learning, including learning in preschool education can help optimize the potential and abilities of preschool education [51-54]. 


\section{Conclusion}

The conclusion from the results of this study is the creation of a sensor-based instrument for measuring basic movement skills for preschool education which has a role in assessing motion in children such as jumping, walking, and running in accordance with the locomotor component motor movement theory. This measuring tool has been proven and validated by motorists. Furthermore, the results of the implementation showed an increase in the motor skills of children aged for the better. So it is hoped that this measuring tool can be used by the wider community in an effort to improve preschool education learning.

\section{$7 \quad$ Acknowledgment}

Thank you to all who have facilitated and contributed to conducting research, the lecturers, and staff at the Faculty, the experts who contributed in providing advice during the implementation of the research. This research activity was also assisted by various other teams to provide comments and information about the motor teaching process. Furthermore, thanks to the staff and operators who facilitated the work in the field.

\section{$8 \quad$ References}

[1] G. Pretto and G. Curró, “An Approach for Doctoral Students Conducting Context-Specific Review of Literature in IT, ICT, and Educational Technology," New Rev. Acad. Libr., vol. 23, no. 1, pp. 60-83, 2017, [Online]. Available: https://doi.org/10.1080/13614533.2016.1227861

[2] O. Fezile, "Attitudes and Opinions of Special Education Candidate Teachers Regarding Digital Technology," World J. Educ. Technol., vol. 9, no. 4, pp. 191-200, 2017, [Online]. Available: https://doi.org/10.18844/wjet.v9i4.2581

[3] S. Salleh and K. Laxman, "Examining the Effect of External Factors and Context Dependent Beliefs of Teachers in the Use of ICT in Teaching: Using an Elaborated Theory of Planned Behavior," J. Educ. Technol. Syst., vol. 43, no. 3, pp. 289-319, 2015. https://doi. org/10.1177/0047239515570578

[4] J. M. Alja, S. A. El-seoud, and M. U. Mwinyi, "Design and Implementation of a Multimediabased Technology Solution to Assist Children with Intellectual Disability to Learn," IJET, vol. 12, no. 4, pp. 141-152, 2017, [Online]. Available: https://doi.org/10.3991/ijet. v12i04.6698

[5] B. Asuman, M. S. H. Khan, and C. K. Clement, "Integration of Web-Based Learning into Higher Education Institutions in Uganda: Teachers' Perspectives," Int. J. Web-Based Learn. Teach. Technol., vol. 13, no. 3, pp. 33-50, 2018, [Online]. Available: https://doi.org/10.4018/ IJWLTT.2018070103

[6] K. Libertus and P. Hauf, "Editorial: Motor Skills and Their Foundational Role for Perceptual, Social, and Cognitive Development," Front. Psychol., vol. 8, 2017, https://doi.org/ 10.3389/fpsyg.2017.00301

[7] N. Wainwright, "The Foundation Phase in Wales, Outdoor Learning and Motor Development," J. Phys. Educ. Sport, vol. 21, no. 1, pp. 567-573, 2021, https://doi.org/10.7752/ jpes.2021.s1064 
[8] S. J. Andajani, A. Wijiastuti, and U. N. Surabaya, "E-Learning Development for Special Education Postgraduate Students," IJET, vol. 15, no. 14, pp. 269-293, 2020, [Online]. Available: https://doi.org/10.3991/ijet.v15i14.13893

[9] X. Li, "Design and Application of Children's Entertainment Education Software in Preschool Education," IJET, vol. 13, no. 7, pp. 201-213, 2018, [Online]. Available: https://doi.org/ 10.3991/ijet.v13i07.8809

[10] L. M. Gagen and N. Getchell, “Using ‘Constraints' to Design Developmentally Appropriate Movement Activities for Preschool Education Education,” Early Child. Educ. J., vol. 34, no. 3, pp. 227-232, 2006, https://doi.org/10.1007/s10643-006-0135-6

[11] J. D. Goodway, R. Famelia, and S. Bakhtiar, "Future Directions in Physical Education \& Sport: Developing Fundamental Motor Competence in the Early Years Is Paramount to Lifelong Physical Activity," Asian Soc. Sci., vol. 10, no. 5, pp. 44-54, 2014. https://doi.org/ $\underline{10.5539 / a s s . v 10 n 5 p 44}$

[12] L. E. Robinson et al., "Motor Competence and its Effect on Positive Developmental Trajectories of Health," Sport. Med., vol. 45, no. 9, pp. 1273-1284, 2015, https://doi.org/10.1007/ $\underline{\text { 440279-015-0351-6 }}$

[13] R. Antunes, A. Bugge, A. K. Ersbøll, D. F. Stodden, and L. B. Andersen, “The Longitudinal Relationship between Motor Competence and Measures of Fatness and Fitness from Childhood into Adolescence," J. Pediatr. (Rio. J)., vol. 95, no. 4, pp. 482-488, 2019, https://doi. org/10.1016/j.jped.2018.02.010

[14] L. M. Barnett et al., "Correlates of Gross Motor Competence in Children and Adolescents: A Systematic Review and Meta-Analysis," Sport. Med., 2016, https://doi.org/10.1007/ s40279-016-0495-Z

[15] B. Holfelder and N. Schott, "Relationship of Fundamental Movement Skills and Physical Activity in Children and Adolescents: A Systematic Review," Psychol. Sport Exerc., vol. 15, no. 4, pp. 382-391, 2014, https://doi.org/10.1016/j.psychsport.2014.03.005

[16] K. K. Palmer, K. M. Chinn, and L. E. Robinson, "The Effect of the CHAMP Intervention on Fundamental Motor Skills and Outdoor Physical Activity in Preschoolers," J. Sport Heal. Sci., vol. 8, no. 2, pp. 98-105, 2019, https://doi.org/10.1016/j.jshs.2018.12.003

[17] E. K. Webster, C. K. Martin, and A. E. Staiano, "Fundamental Motor Skills, Screen-Time, and Physical Activity in Preschoolers," J. Sport Heal. Sci., vol. 8, no. 2, pp. 114-121, 2019, https://doi.org/10.1016/i.jshs.2018.11.006

[18] E. Mazzoli et al., "Feasibility of Breaking Up Sitting Time in Mainstream and Special Schools With a Cognitively Challenging Motor Task," J. Sport Heal. Sci., vol. 8, no. 2, pp. 137-148, 2019, https://doi.org/10.1016/j.jshs.2019.01.002

[19] D. J. Mcdonough, W. Liu, and Z. Gao, "Effects of Physical Activity on Children's Motor Skill Development: A Systematic Review of Randomized Controlled Trials," Biomed Res. Int., vol. 2020, p. 14, 2020, [Online]. Available: https://doi.org/10.1155/2020/8160756

[20] T. Utesch, F. Bardid, D. Büsch, and B. Strauss, "The Relationship Between Motor Competence and Physical Fitness from Preschool education to Early Adulthood: A MetaAnalysis," Sport. Med., no. 0123456789, 2019, https://doi.org/10.1007/s40279-019-01068-y

[21] T. Utesch, D. Dreiskämper, R. Naul, and K. Geukes, "Understanding Physical (in-) Activity, Overweight, and Obesity in Childhood: Effects of Congruence Between Physical SelfConcept and Motor Competence," Sci. Rep., vol. 8, pp. 1-10, 2018, https://doi.org/10.1038/ s41598-018-24139-y

[22] T. Utesch, J. Zinner, and D. Büsch, "Stabilität der physischen Fitness im Kindesalter," Ger. J. Exerc. Sport Res., 2018, https://doi.org/10.1007/s12662-018-0500-9

[23] S. Iivonen and A. K. Sääkslahti, "Preschool Children's Fundamental Motor Skills: A Review of Significant Determinants," Early Child Dev. Care, pp. 1-20, 2013, https://doi.org/10.108 $\underline{0}$ 03004430.2013.837897 
[24] V. I. Cavalheri, L. E. O. N. Straker, D. A. F. Gucciardi, P. A. U. L. A. Gardiner, and Ky. Hill, "Changing Physical Activity and Sedentary Behaviour in People with COPD," Asian Pacific Soc. Respirol., pp. 419-426, 2016, https://doi.org/10.1111/resp.12680

[25] P. T. Katzmarzyk and A. E. Staiano, "Relationship Between Meeting 24-hour Movement Guidelines and Cardiometabolic Risk Factors in Children," J. Phys. Act. Health, 2017, [Online]. Available: https://doi.org/10.1123/jpah.2017-0090

[26] S. Bakhtiar, R. Famelia, and J. D. Goodway, "Needs Assesment of the Fundamental Motor Skills of Urban and Rural Children in Indonesia," J. Sport. Exerc. Psychol., vol. 37, 2015.

[27] E. Bernie, "Seputar Kesehatan Anak," 2013. www.idai.or.id.

[28] K. Wick et al., "Interventions to Promote Fundamental Movement Skills in Childcare and Kindergarten: A Systematic Review and Meta-Analysis," Sport. Med., vol. 47, no. 10, pp. 2045-2068, 2017, https://doi.org/10.1007/s40279-017-0723-1

[29] A. Brian, J. D. Goodway, J. A. Logan, and S. Sutherland, "SKIPing with Teachers: An Early Years Motor Skill Intervention,” Phys. Educ. Sport Pedagog., vol. 22, no. 3, pp. 270-282, 2017. https://doi.org/10.1080/17408989.2016.1176133

[30] A. Brian, J. D. Goodway, J. A. Logan, and S. Sutherland, "SKIPing with Head Start Teachers: Influence of T-SKIP on Object-Control Skills," Res. Q. Exerc. Sport, vol. 88, no. 4, pp. 479-491, 2017, [Online]. Available: https://doi.org/10.1080/02701367.2017.1375077

[31] A. Brian and S. Taunton, "Effectiveness of Motor Skill Intervention Varies Based on Implementation Strategy," Phys. Educ. Sport Pedagog., vol. 23, no. 2, pp. 223-233, 2018, [Online]. Available: https://doi.org/10.1080/17408989.2017.1413709

[32] J. D. Goodway and C. F. Branta, "Influence of a Motor Skill Intervention on Fundamental Motor Skill Development of Disadvantaged Preschool Children," Res. Q. Exerc. Sport, vol. 74, no. 1, pp. 36-46, 2013, [Online]. Available: https://doi.org/10.1080/02701367.2003. $\underline{10609062}$

[33] S. W. Logan, E. K. Webster, N. Getchell, K. A. Pfeiffer, and L. E. Robinson, "Relationship between Fundamental Motor Skill Competence and Physical Activity During Childhood and Adolescence: A Systematic Review," Kinesiol. Rev., vol. 4, no. 4, pp. 416-426, 2015, [Online]. Available: https://doi.org/10.1123/kr.2013-0012

[34] V. Lopes, L. P. Rodrigues, J. A. Maia, and R. Malina, "Motor Coordination as Predictor of Physical Activity in Childhood," Scand. J. Med. Sci. Sports, vol. 21, no. 5, pp. 663-669, 2010, https://doi.org/10.1111/j.1600-0838.2009.01027.x

[35] D. F. Stodden, J. D. Goodway, S. J. Langendorfer, M. E. Rudisill, C. Garcia, and L. E. Garcia, "A Developmental Perspective on the Role of Motor Skill Competence in Physical Activity: An Emergent Relationship," Quest, vol. 60, no. 2, pp. 290-306, 2008. https://doi.org/10.10 $\underline{80 / 00336297.2008 .10483582}$

[36] Alnedral, G. Zonifa, and Yendrizal, "A Volleyball Skills Test Instrument for Advanced-Level Students,” J. Phys. Educ. Sport, vol. 20, no. 3, pp. 2213-2219, 2020, https://doi.org/10.7752/ jpes.2020.s3297

[37] V. L. Kondakov, L. N. Voloshina, E. N. Kopeikina, and L. Kadutskaya, "Daily Assessment of Physical Activity in 6-11-Year-Old Children," J. Phys. Educ. Sport, vol. 20, no. 4, pp. 1673-1680, 2020, https://doi.org/10.7752/jpes.2020.04227

[38] R. Decaprio, Aplikasi Teori Pembelajaran Motorik Di Sekolah. Yogyakarta: DIVSA Press, 2013.

[39] Borg \& Gall, Educational Research: An Introduction Seventh Edition. Boston New York San Francisco: Pearson Educatio, 2003.

[40] S. W. Logan et al., "Fundamental Motor skills: A Systematic Review of Terminology," J. Sports Sci., vol. 36, no. 7, pp. 781-796, 2018, https://doi.org/10.1080/02640414.2017.1 $\underline{340660}$ 
[41] M. Pustišek, Y. Wei, Y. Sun, A. Umek, and A. Kos, "The Role of Technology for Accelerated MotorLearning in Sport,"Pers. Ubiquitous Comput.,2019,[Online].Available: $\underline{\text { ttps://doi.org/ }}$ 10.1007/s00779-019-01274-5

[42] S. David and W. Michael, Typical and Atypical Motor Development British: Clinics in Developmental Medicine. Mac Keith Press, 2018.

[43] R. M. Eime, J. A. Young, J. T. Harvey, M. J. Charity, and W. R. Payne, "A Systematic Review of the Psychological and Social Benefits of Participation in Sport for Children and Adolescents: Informing Development of a Conceptual Model of Health Through Sport," Int. J. Behav. Nutr. Phys. Act., pp. 1-21, 2013, [Online]. Available: https://doi.org/10.1186/ 1479-5868-10-98

[44] M. M. McClelland and C. E. Cameron, "Developing Together: The Role of Executive Function and Motor Skills in Children's Early Academic Lives," Preschool education Research Quarterly, 46, 142-151, 2019. https://eric.ed.gov/?id=ED596838. https://doi.org/10.1016/j. ecresq.2018.03.014

[45] M. Manning, S. Garvis, C. Fleming, and G. T. Wong, "The Relationship between Teacher Qualification and the Quality of the Preschool Education Education and Care Environment," Campbell Systematic Reviews, 13(1), 1-82, 2017. https://doi.org/10.4073/csr.2017.1

[46] A. Brunsek, M. Perlman, O. Falenchuk, E. McMullen, B. Fletcher, and P. S. Shah, "The Relationship between the Preschool Education Environment Rating Scale and its Revised Form and Child Outcomes: A Systematic Review and Meta-Analysis," PloS one, 12(6), e0178512, 2017. https://doi.org/10.1371/journal.pone.0178512

[47] M. Wu, X. Liang, S. Lu, and Z. Wang, "Infant Motor and Cognitive Abilities and Subsequent Executive Function," Infant Behavior and Development, 49, 204-213, 2017. https://doi.org/ 10.1016/j.infbeh.2017.09.005

[48] K. E. Williams, "Moving to the Beat: Using Music, Rhythm, and Movement to Enhance Self-Regulation in Preschool Education Classrooms," International Journal of Preschool education, 50(1), 85-100, 2018. https://doi.org/10.1007/s13158-018-0215-y

[49] A. Komaini (2017, March). Fundamental motor skills of kindergarten students (a survey study of the influence of financial condition, playing activity, and nutritional status). In IOP Conference Series: Materials Science and Engineering (Vol. 180, No. 1, p. 012156). IOP Publishing. https://iopscience.iop.org/article/10.1088/1757-899X/180/1/012156/pdf. https://doi.org/10.1088/1757-899X/180/1/012156

[50] D. Ourdaa, A. Gregoriadisb, K. Mouratidouc, G. Grouiosd, and H. Tsorbatzoudisd, "A Motor Creativity Intervention in the Greek Preschool Education Education Settings: Effects on Beliefs about Health," Journal of Preschool education Education Research, 6(1), 22-42, 2017. https://jecer.org/wp-content/uploads/2017/02/Ourda-Gregoriadis-MouratidouGrouios-Tsorbatzoudis-issue6-1.pdf

[51] J. M. Alja'am, S. A. El-Seoud, and M. U. Mwinyi, "Design and Implementation of a Multimedia-based Technology Solution to Assist Children with Intellectual Disability to Learn," International Journal of Emerging Technologies in Learning, 12(4), 2017. https://doi.org/ 10.3991/ijet.v12i04.6698

[52] X. Li, "Design and Application of Children's Entertainment Education Software in Preschool Education," International Journal of Emerging Technologies in Learning, 13(7), 2018. https://doi.org/10.3991/ijet.v13i07.8809

[53] A. Abdi and N. Cavus, "Developing an Electronic Device to Teach English as a Foreign Language: Educational Toy for Pre-Kindergarten Children," International Journal of Emerging Technologies in Learning (iJET), 14(22), 29-44, 2019. https://doi.org/10.3991/ijet. v14i22.11747 
[54] L. S. Riza, T. Sawiji, E. Budiman, and A. Rosales-Pérez, "A Labyrinth Game for Blind Children Using Problem Solving Learning Model," International Journal of Emerging Technologies in Learning, 15(2), 2020. https://doi.org/10.3991/ijet.v15i02.11375

[55] Ganefri H. Hidayat, I. Kusumaningrum, and A. Mardin, "Needs Analysis of Entrepreneurship Pedagogy of Technology and Vocational Education with Production Based Learning Approach in Higher Education," International Journal of Advanced Science, Engineering and Information Technology, 7, 1701-1707, 2017. https://doi.org/10.18517/ijaseit.7.5.1510

[56] Hidayat, H., Yuliana, "The Influence of Entrepreneurship Education and Family Background on Students' Entrepreneurial Interest in Nutritious Traditional Food Start Ups in Indonesia," International Journal of Engineering and Technology(UAE). 7(4), 118-122, 2018. https:// doi.org/10.14419/ijet.v7i4.9.20631

[57] H. Hidayat, B. Y. Tamin, S. Herawati, Z. Ardi, and A. P. Muji, "The Contribution of Internal Locus of Control and Self-Concept to Career Maturity in Engineering Education," Int. J. Adv. Sci. Eng. Inf. Technol, 10(6), 2282-2289, 2020. https://doi.org/10.18517/ijaseit.10.6.11698

\section{Authors}

Anton Komaini, is a Doctor in Motor Learning. He is a Lecture in Department of Sport Education, Faculty of Sport Science of Universitas Negeri Padang, Padang, Indonesia. His research areas include Motor Learning, and Sport Education.

Hendra Hidayat, $\mathrm{He}$ is a Lecturer in in Department of Electronics Engineering Education, Engineering Faculty of Universitas Negeri Padang, Padang, Indonesia. His research areas include Technical Vocational and Education Training, and Engineering Education.

Ganefri, He is a Senior Lecturer in in Department of Electro Engineering Education, Engineering Faculty of Universitas Negeri Padang, Padang, Indonesia. His research areas include Vocational Education, and Entrpreneurship.

Alnedral, is a Doctor in Sports Coaching and Learning Strategies. He is a Senior Lecture in Department of Sport Education, Faculty of Sport Science of Universitas Negeri Padang, Padang, Indonesia. His research areas include Sports Coaching and Learning Strategies, and Sport Education.

Yanuar Kiram, is a Doctor in Motor Learning. He is a Senior Lecture in Department of Sport Education, Faculty of Sport Science of Universitas Negeri Padang, Padang, Indonesia. His research areas include Motor Learning, and Sport Education.

Gusril, is a Doctor in Motor Learning. He is a Senior Lecture in Department of Sport Education, Faculty of Sport Science of Universitas Negeri Padang, Padang, Indonesia. His research areas include Sport Education.

Deby Tri Mario, is a Master in Sport Education. He is a Lecture in Department of Sport Education, Faculty of Sport Science of Universitas Negeri Padang, Padang, Indonesia. His research areas include Sport Education.

Article submitted 2021-07-07. Resubmitted 2021-08-10. Final acceptance 2021-08-11. Final version published as submitted by the authors. 